Scientific Society. In this way all branches of the natural sciences in Moravia are represented in publications which reflect the high standard of work performed by contemporary Moravian men of science, including discoveries in archæology, geology, ecology and biology in addition to meritorious physicochemical researches.

\section{Mercury Poisoning}

A REview of present knowledge as to the liability of users of mercury to contract mercury poisoning by continued exposure to mercury vapour or to solutions of mercury compounds of small concentration has recently been issued (Rev. Sci. Inst., Aug.). Although there are great differences in the sensitivity to poisoning amongst individuals, it seems certain that prolonged exposure to an atmosphere containing one quarter of a milligram of mercury vapour per cubic metre of air is dangerous. As the saturation vapour pressure of mercury at $18^{\circ} \mathrm{C}$. is such that there is more than $10 \mathrm{mgm}$. of mercury in a cubic metre, it is evident that exposure of considerable surfaces of mercury to air at ordinary temperatures should be avoided. Good ventilation is the best precaution where exposed surfaces are unavoidable, and this failing, gas masks containing carbon-iodine absorber should be used. Rubber gloves should be worn to prevent contact with mercury or mercury solutions.

\section{Optical Utilities}

Messrs. W. Watson and Sons, Ltd., 313 High Holborn, London, W.C.1, have issued a booklet entitled "Optical Utilities", containing a catalogue of small optical instruments for aiding vision. These include magnifiers mounted as spectacles, the "Speera" for dissecting or viewing minute objects, and the "Spectopera" for viewing distant scenes, a magnifying glass with electric bulb in the handle for examining maps, prints, etc., a "Strip" magnifier for reading small print, a pocket lens compass, the needle of which is mounted between two lenses so that it can be used as a pocket magnifier, and other useful devices.

\section{Noise Insulation}

THE valuable summary of the best methods of reducing noise which Dr. G. W. C. Kaye, of the National Physical Laboratory, communicated to the Journal of Scientific Instruments in June has now been issued by the Institute of Physics as a separate publication, and should be in the hands of all designers of structures in which noise is to be diminished as much as possible. The loudest of the offending noises should first be reduced at least to the average level of the others, either by reducing it at its source or by providing fewer facilities for its propagation. Against direct transmission through the air the remedy is to enclose the source or hearer in a sound-proof building, which may require its doors, windows, walls and floors to be heavy or double with intervening air gaps, and to have its walls and ceilings lined with sound absorbing materials. Metal piping should have short lengths replaced by rubber or other less efficient transmitting material, and be supported by insulated clips.

\section{National Research Council of Japan}

THE report of the National Research Council of Japan for the year April 1936-March 1937, which has recently been published, contains a list of serial publications issued during the year, with details of the general meeting, divisional meetings and committee meetings, as well as of the international scientific meetings at which the Council was represented. In addition to the Divisions of Astronomy, Geophysics, Chemistry, Physics, Geology and Geography, Biology and Agriculture, Medical Sciences, Engineering and Mathematics, a Committee of Pacific Investigation has held five meetings and a National Committee on Radio Research ten meetings dealing with the transmission of short waves, measurements of radio waves during the total solar eclipse on June 19, 1936, studies of the ionosphere, etc. The report also gives the personnel of the various divisions and committees and a full list of serial publications received from abroad.

\section{Political and Economic Planning}

A BRoADshemt recently issued by $\mathbf{P}$ E P (Politica and Economic Planning) summarizes the progress oe $\mathrm{P} \mathrm{EP}$ in 1936-38. In the last two years the volum of published P E P work has approximately doubled, five full reports covering electricity supply, international trade, social services, health services and the Press having appeared within sixteen months, besides more than thirty regular numbers of Planning. This result has been attained by a small voluntary body with a budget of less than $£ 10,000$ a year and a paid staff of less than a dozen persons. This in itself is a striking indication of the opportunities which exist for organized thought about the future, and the most significant feature about the work of P E P is probably the extent of the opportunities it has opened up. The results already achieved suggest that by bringing to bear on public problems even a small proportion of the available intelligence and energy, it should be possible to prevent serious national and international difficulties from arising. The broadsheet gives a complete list of reports already issued as well as of the planning broadsheets, and indicates the position of the studies of regional development and industrial location, on the gas industry, on partners in industry and of the inquiry into population policies which have been initiated by $\mathrm{P} E \mathrm{P}$ and on which reports are later to appear.

\section{Science for the People}

ADVANCE reports promise that science will be well shown at the great 1939 exhibitions in Americathe Golden Gate International Exposition in San Francisco and the New York World's Fair (Science Service, Washington, D.C.). Synthetic foods will be manufactured on the spot, and laboratory rats will be fed upon the foods, and have to stand a comparative test against normally fed individuals. A complete 'chemical' garden growing indoors, without sunlight and without soil, will illustrate the production of maize, peas, melons, squash, spinach and lettuce by chemical means and ordinary incandescent light. ing. Electrical apparatus, television, sound amplifying 
equipment, at which the visitor will be able to listen to the footsteps of insects, promise to enlighten the populace regarding the more spectacular aspects of scientific discovery. It is noteworthy that the site of the New York Fair, which used to be a dismal swamp outside Flushing, Long Island, has been converted into turf, suitable for planting the 10,000 trees taken to the place, by chemical treatment of the acid swamp soil.

\section{Current Sunspots}

A FAIRLY large single sunspot of area about 700 millionths of the sun's hemisphere crossed the sun's central meridian on September $25 \cdot 6$ in latitude $10^{\circ} \mathrm{S}$. This was followed by a larger group of stream type which is erossing the disk between September 21 and October 4 in latitude $12^{\circ} \mathrm{S}$., the time of central meridian passage of the group centre being September 27.7. The area of this big group on September 23 was 1,800 millionths of the sun's hemisphere. Spot groups as large as this are more often than not associated with terrestrial magnetic storms, the average time of commencement being about one day after central meridian passage. Two striking examples of the activity of this region of the sun's chromosphere were witnessed at Greenwich on September 20 and 22 with the Hale spectrohelioscope working in $H \alpha$. On September 20 at $14^{\mathrm{h}} 38^{\mathrm{m}}$ U.T., a highly eruptive prominence was observed to spring from this region then passing into view at the sun's east limb. The prominence was unusually brilliant, a photometric measure at $14^{\mathrm{h}} 41^{\mathrm{m}}$ giving a central intensity of 66 per cent (where continuous spectrum $10 \mathrm{~A}$. from the centre of $H \alpha$ at the centre of the disk $=100$ ). There were big differences of measured radial velocity amounting to $225 \mathrm{~km}$./sec. between adjacent filaments at $14^{\mathrm{h}} 54^{\mathrm{m}}$. The prominence rose from its point of origin to a height of some $4^{\prime}(175,000 \mathrm{~km}$.) within 15 minutes. On September 22, an extensive absorption marking on the disk, representing the projected image of a prominence, was observed at $8^{\mathrm{h}} 50^{\mathrm{m}}$ with a velocity of ascent exceeding $260 \mathrm{~km}$./sec. This marking, with both ascending and descending filaments, extended as seen in projection over some $150,000 \mathrm{~km}$. of the chromosphere and partly encircled the leader sunspot. Activity persisted for at least $3 \frac{1}{2}$ hours.

\section{The Night-Sky in October}

SUMmer Time ends on October 2 at $2^{\text {h }}$ U.T. The moon is full on October 9 at $9 \cdot 6^{\mathrm{h}}$ (the Hunter's moon) and new on October 23 at $8 \cdot 7^{\mathrm{h}}$. Lunar conjunctions with the planets occur as follows: On October $5^{\text {d }} 11^{\text {h }}$ with Jupiter ; October $9^{d} 12^{\text {h }}$ with Saturn; October $21^{\mathrm{d}} 4^{\mathrm{h}}$ with Mars; and on October $26^{\mathrm{d}} 0^{\mathrm{h}}$ with Venus. On October $12^{\mathrm{d}}$ at $9^{\mathrm{h}}$, Mars is in conjunction with Neptune. The planet Jupiter is the dominating bright star of the evening skies; in mid-October it souths at about $20^{\mathrm{h}}$. The various phenomena of the four inner satellites may be followed with the help of data given on pp. 618-619 of the Nautical Almanac for 1938 or in abbreviated form on p. 170 of Whitaker's Almanack. On October 16, Venus is at greatest brilliancy; but the planet sets 43 minutes after the sun. Saturn is on the southern meridian at about $23 \frac{1}{4} \mathrm{~h}$ in mid-October ; on October 8, it is in opposition, the distance from the earth being about $781 \frac{1}{4}$ million miles. Mars is a morning star rising at $3 \frac{3 \mathrm{~h}}{4}$ in the middle of the month. Two well-known variable stars are now well placed for observation during the late evenings. - Ceti, the variability of which was first recognized by Fabricius in 1596, is a long-period irregular variable. At maximum the star is usually of magnitude 3 or 4 , but is occasionally of magnitude 2 ; at minimum it sinks to magnitude 9 . The period is about $\mathbf{3 3 0}$ days. A maximum is expected near the beginning of October. The other variable, Algol ( $\beta$ Persei), is an eclipsing binary the periodic variations in brightness of which were discovered by Goodricke in $\mathbf{1 7 8 2}$ as occurring at regular intervals of 2 days 20 hours 49 minutes. There are several meteor radiants listed for October; the Orionids are seen at a maximum during October 18-20. On moonless nights, the great nebula in Andromeda, visible to the naked eye, may easily be located with the help of binoculars. The Pleiades are now well above the eastern horizon in the late evening.

\section{Announcements}

The Right Hon. the Earl of Athlone, chancellor of the University of London, will open the new buildings of Queen Mary College on October 12 at 3 p.m.

Sir Malcolm Watson will speak on "Malaria and Empire Development" at a joint meeting at 18 Northumberland Avenue, London, W.C.2, of the Planters' and Empire Social Services' Groups of the British Empire Society on October 6 at 8 p.m.

Dr. H. T. Calvert, chemical inspector at the Ministry of Health, will open a discussion on the present trend of sewage purification at a meeting of the Royal Sanitary Institute, 90 Buckingham Palace Road, London, on October 11 at 5.30 p.m.

THE Danish Institute for Human Heredity and Racial Hygiene at Copenhagen is to be incorporated in the University under the direction of Dr. Kemp.

17,330 persons have recently died of cholera in the United Provinces in the north of India during an epidemic reported to be one of the worst for many years. Bodies of victims are thrown into rivers that supply drinking water, and religious Hindus, many infected with cholera, continue to bathe in the Ganges. Mass inoculation of exposed persons and disinfection of dwellings have been carried out.

A NEw law has recently been passed in the Argentine Republic of which the principal enactments are (1) the abolition of licensed prostitution, (2) compulsory treatment for venereal disease, (3) penalties for wilful transmission of venereal disease, (4) prenuptial medical examination, which is compulsory for men and optional for women, (5) prohibition of quack advertisements for the cure of venereal diseases. 